\title{
ROMANTICISMO E HISTERIA EN ESPAÑA
}

\author{
David T. GIES \\ University of Virginia
}

El XIX es, en las palabras de Evelyne Ender, un siglo obsesionado por la «gender-marked subjectivity» (Ender 1995, pág. 5). Ender analiza los casos de histeria en la novela inglesa y francesa, pero como nos ha enseñado Montserrat Ribao Pereira (Ribao 1999), una de las figuras más representativas del drama romántico español es esa mujer vestida de blanco, con el cabello suelto, que sufre la obnubilación, la locura o el enajenamiento. Es decir, la mujer histérica.' Esta figura clave simboliza las potentes emociones que caracterizan la literatura del período romántico tanto en Europa como en España. Tan frecuente es la imagen en los escenarios melodramáticos y románticos españoles ( $\mathrm{y}$, huelga decir, opcrísticos también), que un periodista de Cádiz ya puede hacer burla del fenómeno en 1843, al notar que la mujer histérica y encarcelada tiene el pelo suelto porque, «QQuién ticne ganas de peinarse y encuentra peluquero en el calabozo!» (Simón Palmer 1984, pág. 176).

Sin embargo, la histeria no es una enfermedad exclusivamente literaria, como bien sabemos. Aunque como fenómeno médico se remonta a la Antigüedad (enfermedad puramente femenina, «uterina»; viene de la palabra griega que significa «útero»), «irrumpe» en el siglo XIX con una fuerza insólita (parecida a lo que hoy en día llamamos un «media event» [Beizer 1995, pág. 3]). Los médicos ya

' Ribao toma sus ejcmplos de obras canónicas como La conjuración de Venecia (Francisco Martínez de la Rosa, 1834)y El trovador (Antonio García Gutiérrez, 1836), y de obras menos conocidas como Doña Mencia (Juan Eugenio Hartzenbusch, 1838), Pedrarias Dávila (Pedro Gorostiza, 1838), El rey monje (Antonio García Gutiérrez, 1839) y Laura o la venganza de un esclavo (José María Diaz, 1839). 
habían creado una tipología de la histeria, relacionando los síntomas con el cuerpo femenino o con la conciencia (lo que llama Elisabeth Bronfen «the hysteric's bodily enactment of psychic discontent and anguish» [Bronfen 1998, pág. xi]). $\mathrm{Y}$ las manifestaciones de la conciencia incluyen el coma, el delirio, las ilusiones espectrales y el sonambulismo (Laycock 1840, pág. 149). Es tan frecuente la histeria en el siglo XIX que según el Dr. Pierre Briquet (un contemporáneo de Flaubert), una de cada cuatro mujeres ( $y$, en casos muy raros, hombres afeminados) la padecían²; llega a cobrar proporciones casi epidémicas en la Europa occidental a mediados del siglo XIX -lo que llamará Jules Claretie en 1881 «la grande maladie du siècle. $\aleph^{3}$ Los médicos franceses (Bichat, Brachet, Briquet, Cabanis, etc.) ya habían producido una impresionante cantidad de estudios sobre la histeria y es el mismo Flaubert quien ofrece el caso de histeria femenina por excelencia en su heroína Emma Bovary (recordemos que el autor confiesa que «Mme. Bovary, c'est moi»). También a mediados del siglo George Sand, en una carta a Flaubert, expresa lo que es, según su definición, la histeria:

Qu'est-ce que c'est aussi d'être histérique? Je l'ai peut-être aussi, je le suis peut-être, mais je n'en sais rein, n'ayant jamais approfondi la chose et en ayant ouï parler sans l'étudier. N'est-ce pas un malaise, une angoisse causés par le désir d'un impossible quelconque? En ce cas, nous en sommes tous atteints, de ce mal étrange, quand nous avons de l'imagination; et porquoi une telle maladie aurait-elle un sexe? (Sand 1964, vol. XX, pág. 297)

Es decir, ya en fechas tempranas esta condición es conocida, estudiada y comentada en la prensa médica europea. No nos extraña que se vislumbrara con tanta intensidad en la literatura.

Según los médicos y teóricos ( $\mathrm{y}$, hay que confesarlo, los charlatanes también) que estudian el fenómeno, la causa principal que condiciona la histeria es la feminidad y la causa determinante es el exceso de emoción (Ender 1995, pág. 37). Briquet declara que «La femme est faite pour sentir et sentir c'est presque 1'hystérie» (Briquet 1859, pág. 50), prejuicio compartido por los médicos y comentaristas españoles como (por citar sólo un ejemplo) Baltasar de Viguera, que en 1827 escribe:

${ }^{2}$ Briquet es autor también de un tratado sobre la histeria, Traité clinique et thérapeutique de l'hystérie (Briquet 1859). Flaubert dice que estudió esta obra (y otras) antes de escribir su famosa novela (Ender 1995, pág. 26).

${ }^{3}$ Jules Claretie, Les Amours d'un inerne (Apud. Beizer 1999, pág. 15). Curiosamente, la misma palabra («epidemia») se usa para explicar un fenómeno parecido en el México del siglo XVIII, nota sacada de un artículo todavía sin publicar de Beatriz Quintanilla-Madero (expreso mi agradecimiento a mis colegas Catherine Jaffe y Elizabeth Franklin Lewis, editoras del libro titulado La Ilustración de Eva: The Experience of Hispanic Women, de donde saco esta información). 
La muy fina excitabilidad de todos los órganos, y las extraordinarias modificaciones y fases de que es fácilmente afecta esta propiedad en lo físico y moral, es cabalmente lo que constituye el carácter específico del bello sexo. Admira, pues, el ver los grados a que puede remontarse y matices de que es susceptible su delicada sensibilidad. Todos sus sentidos, todos los puntos de su constitución, y cada uno separadamente poseen esta calidad en lo máximo; todos representan el papel que corresponde a la índole de su sexo, y en todos brillan espontáneamente los sublimes rasgos de éste su más hermoso distintivo (Apud. Jagoe 1998, pág. 372).

Semejantes características presentan Laura en La conjuración de Venecia (II, 2), Inés en Carlos II el hechizado (V, 7), e incluso Leonor en la novela de Larra, El doncel de don Enrique el Doliente (donde repite al final, «Ya es tarde, ya es tarde,» despeluchada y con los ojos desorbitados.) Ribao acierta al insistir en que la locura femenina en el drama romántico español es «consecuencia fatídica de una pasión imposible» (pág. 185); la condición de la histérica es, según Bollas, inherentemente «teatral» (Bollas 2000, pág 116).

En su excelente libro sobre la histeria en la literatura francesa, Janet Beizer detalla cómo la histeria se transforma en metáfora, en un fenómeno que caracteriza la cultura francesa en un momento de ansiedad y caos, lo que ella llama «la histerización de la cultura» (Beizer 1999, pág. 8). La mujer histérica se convierte en «emblema» de ese caos: «Fashioned in the image of the times, the hysteric offers surface glitter and inner disarray. Fastened onto the hysteric's almost totemic form is the anxiety of an age» (Beizer 1999, pág. 9). Beizer documenta esta proyección (de la ansiedad sobre el cuerpo de la mujer histérica) en la novela francesa de mediados del siglo, pero creo que en España la figura de la mujer hipersensible, recargada de emociones e histérica ya se ve desde los años 1820 en el teatro. Claro, con frecuencia esa figura es un préstamo de la literatura melodramática inglesa y francesa (ver Felski 2003) pero su continua proyección sobre la cultura española durante la época romántica es notable y establece la base, en cierto modo, de la interpretación de la mujer que domina la cultura española durante todo el siglo.

Uno de los primeros, y más poderosos, casos de la mujer histérica se encuentra en el melodrama traducido/adaptado y de inmediato estrenado por Juan de Grimaldi en Madrid en 1825, El abate L'Epée y el asesino, o La huérfana de Bruselas (conocido popularmente como La huérfana de Bruselas [ver Gies 2002]). La mujer de Grimaldi, Concepción Rodríguez, hizo el papel de la heroína, la epónima huérfana Cristina, y lo hizo con tanta pasión que no sólo encontró el éxito sino que el papel quedó asociado a ella durante toda su carrera teatral. La obra desborda pasión, espectáculo, misterio, muerte, venganza, amor frustrado, tiranía, injusticia, patetismo y sentimiento, es decir, todos los ingredientes que 
gustaban tanto en Francia en las primeras décadas del XIX y que anticipan las características del drama romántico durante los años 1830. Este «drama de espectáculo,» como reza la portada, presenta a personajes que son, más que individuos, tipos: el malo de la película (el tirano, Válter), el padre cruel (el abate), el novio ameno aunque tontito (Carlos) y, claro está, la pobre huérfana inocente (Cristina). La obra se abre en un espacio simbólico, clausurado y cerrado, es decir, femenino: «El teatro representa el jardín de la quinta de Belvil: está cerrado en el foro por una reja, que se abre en el medio.» Así, el autor nos presenta desde el principio (y en el reparto los primeros cuatro personajes son mujeres) con un mundo tildado de femenino, un espacio fuertemente identificado ya con la mujer, con esa mujer «cerrada» y con «reja.» Cristina encapsula las cualidades que se van a repetir ad nauseam en el teatro romántico: es una chica desamparada, huérfana, pobre, joven, «como un ángel» $(\mathrm{I}, 3)$ y enclaustrada en la finca. Llora mucho con esas lágrimas que simbolizan no sólo la tristeza humana sino también la debilidad e inestabilidad de la protagonista (ver Sebold 1983). Ya desde el principio el autor la marca como un ser débil: «Vamos... es preciso... Me faltan las fuerzas... Mi vista se turba... No puedo tenerme en pie» $(\mathrm{I}, 10)$. Al contar su triste historia, toda llena de imágenes de la oscuridad y la confusión, el espectador ve que ella no tiene ningún protagonismo en su propia vida. Es un ser manipulado por los hombres. Las cosas le pasan, las decisiones se toman sin su intervención. "Con que ya se decidió mi suerte,» lamenta $(I, 8)$. Durante muchas escenas, ella ni siquiera tiene voz, no habla, no opina delante de la autoridad patriarcal (el abate o Carlos). Y, hay que señalarlo, es simbólicamente «ciega»: «A Cristina que se ha cubierto los ojos con un pañuelo» $(1,11)$.

Cuando Cristina por fin cobra un poco de fuerza, en un intento de resistir las presiones de Válter (II, 4), cuando parece que va a poder descubrir su poder como ser humano, esas fuerzas le fallan. Se desmaya (o sea, vuelve a su estado «sin palabra») y está como muerta («tiene las manos como nieve,» II, 5). Aunque Válter tiene pruebas de su inocencia, no se las va a revelar si Cristina no se casa con él. Ella sufre el destierro del Jardín del Edén: la marquesa la echa de casa, pintándola como criminal, deshonrada, mentirosa y fugitiva. Este «ángel», sin embargo, no goza del mundo edénico reservado a los ángeles; todo lo contrario. Ya en el segundo acto comienza a enloquecer: «Todos van a precipitarse. Cristina aparece en lo alto de la escalera, en medio de las llamas: pálida, el pelo caído, con un puñal ensangrentado en la mano» (II, 16). Ese «pelo caido» ya señala a los espectadores la condición de Cristina.

Al final de la obra, Cristina se ha convertido en un símbolo de la histeria melodramática, esa «expresión simbólica de la paranoia decimonónica» de que habla Felski (152). En el Acto III la encontramos medio enloquecida, incapaz de tomar decisiones, de actuar de una manera lógica ni racional. Su criada Águeda 
dice, «Allí está desmayándose a cada momento... Luego sale, figura estar en Bruselas, se defiende como si estuviera acusada, y está diciendo sobre aquello un millón de disparates. En fin, diría una que perdió el juicio la muchacha» (III, 2). Cristina, aceptando otras características atribuídas a la mujer de la época, asume la culpabilidad, se cree culpable, aunque no lo es. El culpable es Válter, pero esto sólo se prueba después de una conversión importante - la conversión de Cristina primero en cadáver (creen que se ha muerto en el incendio) y luego en espectro enloquecido:

Todos se retiran, y dejan libre el paso hasta la puerta del fondo. Válter esforzándose a disimular su turbación, se acerca titubeando y parándose varias veces. Todos le miran. Llegando a la puerta, se abre y aparece Cristina con un vestido blanco, el pelo suclto en los hombros, y con una mano señalando a Válter. (III, 13)

Aquí tencmos la imagen paradigmática, la que se repitirá a lo largo del periódo romántico (y más allá): la mujer vestida de blanco (ángel), con el pelo suelto, medio enloquecida o casi muerta («yo fallezco,» dice Cristina).

Se acumulan los ejemplos, como ha detallado Ribao. José María Díaz capta esta conceptualización simbólica del cuerpo de la mujer en 1839, en su drama histórico Laura o la venganza de un esclavo, que, en cuanto a la presentación de la heroína, tiene muchas semejanzas con La huérfana de Bruselas. Laura no fue representada nunca en Madrid (sí en las provincias, donde provocó escándalo), pero sí se publicó en por lo menos dos ediciones, según González Subías (2004, pág. 244). Como ha señalado Ribao, leemos en ella la siguiente acotación:

La fisonomía de Laura toma una expresión terrible: violentas convulsiones, con ojos desencajados contempla a Gustavo, y en el delirio más espantoso exclama. [...] Laura va clamándose por momentos. [...] La fisonomía de Laura va tomando por momentos un aspecto más tranquilo. [...] estrecha la mano de Gustavo. Su fisonomía se altera y toma una expresión horrible. (Ribao 1999. pág. 197)

Pero Díaz no la deja así. Al contrario, Laura sirve como puente entre la mujer histérica romántica y la mujer doméstica realista: en el epílogo del drama, Laura, mirando al cielo, muere en los brazos de Gustavo y, como doña Inés y don Juan, sube al cielo («Gustavo: ;Sube al cielo, madre mía!»). Mujeres histéricas semejantes las encontramos en Doña Jimena de Ordóñez (1838), de Gregorio Romero Larrañaga; en El bastardo (1838), de Antonio García Gutiérrez; en Rosamunda (1839), de Antonio Gil y Zárate; en Elvira de Albornoz (1836), de José María Díaz; etc.

Otro caso emblemático es el elaborado por la dramaturga más conocida del siglo, Gertrudis Gómez de Avellaneda. La curiosa pero encantadora comedia, La 
hija de las flores, se estrenó en el Teatro del Príncipe en 1852. «Curiosa» porque es, en parte, una inversión del patrón creado por Leandro Fernández de Moratín en El si de las niñas (la elección de un marido, la desigualdad de edad, etc.). Pero la desigualdad de edad aquí afecta a un muchacho joven (Luis tiene 23 años) y una mujer mayor que él (Inés tiene 36). El padre de Inés, el barón, quiere que se case porque no quiere dejar su cuantiosa herencia en manos de una mujer inestable (en su opinión); pide un nieto. Inés, pintada por la dramaturga y por los otros personajes como loca (I, 3; I, 12), se desmaya con frecuencia (III, 1); y tiene «espasmos convulsivos,» según su nodriza Beatriz (II, 12). Y por fin, cuando tiene que revelar su complicada y trágica historia, adopta la misma postura que hemos visto en otras heroínas: «Sale Inés a la escena, desmelenada, el rostro desencajado, y desordenado el vestido» (III, 13), en perfecto símbolo cósmico de su desorden mental y existencial. Su locura procede de una experiencia de su juventud, cuando fue violada ${ }^{4} \mathrm{y}$ impregnada por un hombre -cuya identidad sólo se revela después - y quedó encinta como consecuencia de esa violación. La hija, que Inés cree muerta, será, obviamente, la «hija de las flores» del título de la obra. Y si Flora es la hija de Inés (que se desmaya de nuevo en III, 13), un matrimonio entre Inés y el Conde puede legitimar a Flora y evitar la tragedia; el Barón tendrá nieta.

Ya se conocen muchos ejemplos de esta figura en la literatura romántica (ver el artículo de Ribao), pero para seguir señalando su trascendencia, nos conviene mirar el caso de Enriqueta Lozano de Vilchez, cuyo drama María o la abnegación, de 1854, lo protagoniza ya otra heroína histérica. Ya desde el título, sabemos que estamos ante una obra que capta uno de los conceptos clave de la «misión de la mujer,» es decir, la abnegación. La mujer que lo sacrifica todo por el bien de su familia o por el amor (como intentó hacer Cristina) es la auténtica heroína de estas obras. Lozano presenta un conflicto entre dos mujeres: María, la mujer abnegada y apasionada, es inocente y buena; Ángela, la mujer poderosa y ambiciosa, es conspiradora y mala. El objeto de deseo de las dos mujeres, Raúl, al final tiene que decidir entre el amor (María) o la ambición (Ángela). María se mantiene firme en su abnegación, su paciencia y su incapacidad: ya dispuesta a «venderse» para salvar a su amante, la heroína se convierte en estatua -en algo «inmóvil» como un cadáver-y se queda sin voz. A partir de ahí, su transformación en la mujer enloquecida que ya hemos visto en estos dramas es rápida:

María ha quedado inmóvil a las últimas palabras del doctor; su rostro debe manifestar la lucha que la agita, y al oir la maldición de su padre lanza una carcajada convulsiva y nerviosa. (II, 14)

${ }^{4}$ Lou Charnon Deutsch comenta la figura de la mujer violada como imagen «desflorada» («deflowered») (Charnon Deuttsch 2000, pág. 252). 
En el tercer, y último, acto María está totalmente desquiciada (su padre confirma que «se halla tan abatida») y la encontramos riéndose locamente: «En la alteración de su rostro y en el desaliño de su traje deja conocer su locura. Después de mirar en torno, dice lentamente y con voz tristísima...» (III, 2). Y ahora, totalmente enloquecida, María está dispuesta a sacrificarlo todo; se cree culpable de todo. Cuando ya no puede más, se desmaya y va perdiendo vida («Más que pálida estás! Tu mano fría / al sostenerte trémula no acierta [...] Tiembla, está yerta» (III, 8). Muere simbólicamente: «(Con un grito del alma y cayendo en un sillón). Adiós por siempre: le perdí... yo muero» (III, 9). María lo ha perdido todo, lo ha sacrificado todo - le ha dado a Raúl dinero (las joyas de su madre), perdón y una mujer (Ángela). Pero como mujer abnegada y sacrificial, puede morir feliz: «iAy! Se han salvado / ya puedo morir» (III, 11). Como la Inés de Don Juan Tenorio, esta heroína intercede para conseguir la felicidad del hombre. Si antes de la aparición de Inés (1844) estas mujeres sólo sugieren la imagen del ángel, Inés es un ángel, literalmente convertida en espíritu celestial por el dramaturgo, enviada del Cielo para salvar a Don Juan.

Estos elementos ya son tópicos en las novelas góticas inglesas y francesas de principios de siglo (ver Delamotte y Lévy), pero su uso en el teatro español confirma hasta qué punto España interiorizó dichas imágenes en su literatura dramática. Todos las características que definen lo gótico - el miedo, la angustia, la amenaza de violencia, la falta de control del mundo natural, el desorden, la obsesión, la falta de la razón - se incriben en el cuerpo de la mujer protagonista y simbolizan lo que ha fallado en el universo. El vestido blanco simboliza su inocencia y pureza; ella es la oveja sacrificial forzada a entregar su cuerpo para restablecer el orden natural. (Nos preguntamos si el mundo masculino exige la locura de la mujer para poder volver a establecer el orden «natural,» es decir, el orden doméstico). Si la mujer - y su cuerpo— son el sitio de la histeria, entonces ese cuerpo tiene que ser o destruído o reformado para volver al orden «natural». Por eso el cuerpo femenino simboliza ese caos y desorden románticos.

Esta figura dura hasta finales del siglo. En su artículo sobre «La nerviosa»" en Las españolas pintadas por los españoles, P. Ximenez Cros acepta la causa ginecológica de ese trastorno femenino (aunque no menciona directamente la menstruación ${ }^{5}$ dice que esta «nerviosa» comienza a demostrar síntomas de la enfermedad al cumplir 15 años). Según Beizer:

${ }^{5}$ En 1831 George Tate adscribe las causas de la histeria a «an irregular of defective menstruation» (Tate 1831, pág. 11). Insiste en que todos los casos de la histeria se ven en mujeres de entre trece y cuarenta y cinco años de edad (Tate 1831, pág. 16). Sigue: «It is characterized by alternate fits of laughing and weeping, starting and screaming, lying still as death, and struggling with gigantic strength. Generally, there is a loud rumbling in the bowels called Clangor Intestinorum, and the 
For almost forty centuries, from ancient Egypt through nineteenth-century France, the discourse of hysteria manifested an essential continuity in its association of the disease with femininity, sexuality, mobility, fluidity, and aphasia. If the nineteenth century marked a rupture, it was less with theory than with praxis: with the uses or exploitation of hysteria. From about the second third of the century onward, with gathering force in the 1860s, the disease figured prominently in literature, newspapers, journals, salons, and eventually, the street. By the 188 os it had spread through the novel in near epidemic proportions. (BEIZER 1995, pág. 8)

Pero más que la causa, es el comportamiento de la joven descrita por Ximenez Cros que nos interesa. Cuando le pasa algo desagradable - en este ejemplo, una criada mancha su vestido con unas gotas de aceite — su reacción es la de las mujeres histéricas ya vistas en el drama.

Gritó, pateó, lloró, insultó de lo lindo a la culpable, quiso pegarle, rompió en su cólera la inmaculada falda, arrojó las flores, se deshizo el peinado, se mesó los cabellos, se arañó el rostro, hasta que, presa de un terrible accidente, al fin cayó exánime entre los brazos de su asustado padre. (Ximénez Cros 1871, págs. 14-15)

Esta mujer salta entonces de la literatura a la vida; forma parte de «esa falange numerosísima» (Ximénez Cros 1871, pág. 17) que permanece en la imaginación popular. Y es, significativamente, un fenómeno no europeo sino específicamente español, según Ximenez Cros: «jOh, las nerviosas! Las nerviosas son hoy una verdadera plaga en nuestra España» (Ximénez Cros 1871, pág. 17). La mujer histérica, institucionalizada a finales del siglo (Stoddart 2001, pág. 112) ya está en evidencia desde el auge del Romanticismo.

En 1884 la dramaturga J. M. Farnés publica en Barcelona un drama en cuatro actos, Elena de Villers. Es un drama histórico, demasiado largo, melodramático y repetitivo para interesar hoy en día, pero capta perfectamente el personaje que estamos intentando describir aquí. Las protagonistas son mujeres fuertes que están en el centro de la acción durante todo el drama; no sufren la marginalización doméstica que es el destino de tantas mujeres ficticias de la época. Sin embargo, el complicado desenlace contiene la figura que ya ha llegado a ser tan identificada (e identificable) en el teatro: la mujer histérica. Preguntan por Elena, que ha desaparecido tras creer que ha muerto su hijo. Robert pide información sobre su mujer y le dicen que «vuestra desdichada esposa perdió la razón al estrechar contra su pecho el cadáver de su padre» $(\mathrm{IV}, 6) \mathrm{y}$, efectivamente, al entrar en la escena (IV, 8), la acotación confirma su locura: «Elena, vestida de blanco con las trenzas

Globus Hystericus, as it is called, which is, in fact, mere flatulence, causing a sensation like that of a solid ball rising in the throat and producing a sense of suffocation» (Tate 1831, pág. 16). 
de sus cabellos sueltas, aparece por la puerta del foro mirando con demencia a todos.» Pero lo interesante de esta obra, por lo menos desde nuestra perspectiva, es que la mujer no se recupera de su demencia (como es normal en los melodramas) sino que se queda en estado de locura permanente. Lo confirma su inocente hijo: «Papá...mi pobre mamá todavía está loca» (IV, 11). El «ángel de la casa» está desquiciado, comentario seguramente intencionado por parte de Farnés, que escribe para contradecir la norma social. En esta interpretación de la «misión de la mujer,» no hay posibilidad de un «happy ending.»

Existe una conexión íntima entre la histeria, el género y la representación, conexión que se inserta fuertemente en el imaginario español del siglo XIX. Ribao recuerda que

La puesta en escena de la locura es de un enorme valor ornamental, efectista, melodramático incluso. A ello contribuye tanto la apariencia externa tradicionalmente ligada a ella (cabellos sueltos, atuendo desaliñado, ojos perdidos...), como la asociación visual o verbal a elementos especialmente impactantes (mazmorras, tumbas, ataúdes, espacios de ajusticiamiento...), o su lenguaje. [....] cuya estética, al servicio de la espectacularidad, permite la representación plástica y efectista de esa otra realidad, la inconsciente, donde en muchos casos radica el auténtico protagonismo del personaje femenino que vive y sufre la pérdida de la razón. (Ribao 1999, pág. 198)

La literatura (y las imágenes publicadas en la prensa) en el siglo XIX confirman abundantemente que la mujer se asocia con la histeria. La histeria se entiende como táctica femenina de desahogarse de esa «hiperestesia de los sentidos» (Dykstra 1986, pág. 243) a la que la mujer se creía propensa. La psicología moderna confirma esta observación: Laplanche y Pontalis definen la histeria como «una enfermedad por representación» (Laplanche y Pontalis 1981, pág. 178) en su Vocabulaire de la psychanalyse, definición que nos ayuda a entender cómo la enfermedad llega a convertirse en símbolo del mal femenino en el siglo XIX. Ender comenta que obras de esta índole «draw attention to the fact that gender is the product of such a theater» (Ender 1995, pág. 3). Lo visual anticipa lo semántico; es una expresión simbólica de su condición (desquiciada) de mujer (ver Felski 2003, pág. 152), una «expresión espectacular del fastidio universal») (Ribao 1999, pág. 185). Podemos entender ahora con más claridad por qué la imagen de la mujer histérica, vestida de blanco y con el cabello suelto, llega a ser tan común en el teatro español de la época. 


\section{BIBLIOGRAFÍA}

Armstrong, Nancy, 1987. Desire and Domestic Fiction: A Political History of the Novel, New York, Oxford U P.

BEIZER, Janet, 1995. Ventriloquized Bodies. Narratives of Hysteria in NineteenthCentury France, Ithaca, Cornell U P.

BICHAT, Xavier, 1801. Traité d'anatomie descriptive, 5 vols., Paris, Gabon, Brosson.

BOLLAS, Christopher, 2000. Hysteria, New York, Routledge.

BRACHET, Jean-Louis, 1847. Traité de l'hystérie, Paris, Baillière.

Breur, Josef y Sigmund Freud, 2000. Studies on Hysteria, James StracheY (trad.), New York, Basic Books.

Briquet, Pierre, 1859. Traité clinique et thérapeutique de l'hystérie, Paris, Baillière.

Bronfen, Elisabeth, 1998. The Knotted Subject. Hysteria and Its Discontents. Princeton, Princeton U P.

BUTLER, Judith, 1990. Gender Trouble: Feminism and the Subversion of Identity, New York, Routledge.

CABANIS, Pierre Jean Georges, 1815. Rapport du physique et du moral de l'homme, 2 vols., Paris, Caille et Ravier.

Charnon Deutsch, Lou, 2000. Fictions of the Feminine in the NineteenthCentury Spanish Press, University Park, PA, The Pennsylvania State U P.

DíAz, José María, 1839. Laura o la venganza de un esclavo, Madrid, Ignacio Boix.

DelamotTe, Eugenia C., 1990. Perils of the Night. A Feminist Study of NineteenthCentury Gothic, New York, Oxford U P.

DYKSTRA, Bram, 1986. Idols of Perversity. Fantasies of Feminine Evil in Fin-desiècle Culture, New York: Oxford U P.

ENDER, Evelyne, 1995. Sexing the Mind. Nineteenth-Century Fictions of Hysteria, Ithaca, Cornell U P.

FARNÉS, J. M., 1884. Elena de Villers, Barcelona, Imprenta Peninsular.

FELMAN, Shoshana, 1993. What Does a Woman Want? Reading and Sexual Difference, Baltimore, Johns Hopkins U P.

FELSKI, Rita, 2003. Literature After Feminism, Chicago, U Chicago P.

GIES, David T., 2002. «Otra vez Grimaldi: Bouilly, Ducange y La huérfana de Bruselas (1825), , en Francisco LAFARGA, Concepción PALACIOS y Alfonso SAURA (eds.), Neoclásicos y románticos ante la traducción, Murcia, Universidad de Murcia, págs. 309-318.

GONZÁLEZ Subías, José Luis, 2004. Un dramaturgo romántico olvidado: José Maria Díaz, Madrid, Fundación Universitaria Española. 
GRIMALDI, Juan de, [1825] 1862. El abate l'Epée y el asesino, o La huérfana de Bruselas, Madrid, Pascual Conesa.

Jagoe, Catherine, Alda Blanco y Cristina EnRíQuez de Salamanca (eds.), 1998. La mujer en los dicursos de género, Madrid, Icaria.

KaHANE, Claire, 1995. Passions of the Voice. Hysteria, Narrative, and the Figure of the Speaking Woman, 1850-1915, Baltimore, MD, Johns Hopkins U P.

LAPLANCHE, Jean, y Jean-Bernard PONTALIS, 1981. Vocabulaire de la psychanalyse, Paris, Presses Universitaires de France.

LAYCOCK, Thomas, 1840. An Essay on Hysteria: Being an Analysis of its Irregular and Aggravated Forms, Including Hysterical Hemmorrhage, and Hysterical Ischuria, Philadelphia, Haswell, Barrington, and Haswell.

LÉVY, Maurice, 1968. Le roman 'gothique' anglais, 1764-1824, Toulouse, Association des Publications de la Faculté des Lettres et Sciences Humaines de Toulouse.

LiTTLE, Arthur L., Jr., 1993. «'Transshaped' Women: Virginity and Hysteria in The Changeling» en James REDMOND (ed.), Madness in Drama, Cambridge, Cambridge U P, págs. 19-42.

RIBAO PEREIRA, Montserrat, 1999. «La locura femenina como resorte espectacular: Obnubilación, delirio y demencia en el drama romántico,» en Letras Peninsulares 12.2, págs. 185-199.

Sand, George, 1964. Correspondence, Georges LubIN (ed.), Paris, Garnier Frères, 25 vols.

SEBOLD, Russell P., 1983. «'Una lágrima, pero una lágrima sola’: Sobre el llanto romántico,» en Trayectoria del romanticismo español, Barcelona, Editorial Crítica, págs. 185-194.

Simón Palmer, María del Carmen, 1984. «Ecos románticos en la prensa de la época,» en Romanticismo 2, págs. 175-179.

STODDART, Helen, 2001. «The Passion of New Eve and the Cinema: Hysteria, Spectacle, Masquerade,» en Fred BotTing (ed.), The Gothic, Cambridge, D.S. Brewer, págs. 111-131.

TATE, George, 1831. Treatise on Hysteria, Philadelphia, E. L. Carey y A. Hart.

VigueRA, Baltasar de, 1827. La fisiología y patología de la mujer, en JAGOE (1998), págs. 369-386.

XIMÉNez CRós, P. «La nerviosa,» en Roberto Robert (ed.), Las españolas pintadas por los españoles. Colección de estudios acerca de los apsectos, estados, costumbres y cualidades generales de nuestras contemporáneas, Madrid, J. E. Morete, págs. 13-20. 